\title{
Increased in-vitro and in-vivo biological activity of lipopolysaccharide extracted from clinical low virulence vacA genotype Helicobacter pylori strains
}

\author{
FERNANDO SALGADO, APOLINARIA GARCÍA, ANGEL OÑATE, CARLOS GONZÁLEZ and \\ FERNANDO KAWAGUCHI*
}

Departamento de Microbiología, Facultad de Ciencias Biológicas, Universidad de Concepción and * Laboratorio de Gastroenterología, Hospital del Trabajador, ACHS, Concepción, Chile

\begin{abstract}
Helicobacter pylori infection in man is associated with chronic gastritis and peptic ulcer disease. The virulence factors of the species are still under investigation. Among these, the lipopolysaccharide (LPS) is a potential pathogenic factor of the micro-organism, whose biological activity can be estimated by immunological parameters. The aim of this study was to determine the ability of pure LPS extracted from clinical isolates of $\boldsymbol{H}$. pylori to induce mitogenicity, secretion of tumour necrosis factor-alpha (TNF- $\alpha$ ), and spleen growth in a murine model. Rough and smooth LPS from Salmonella typhimurium were used as controls. The results showed that, like the control LPS, all extracts of LPS induced mitogenic activity, stimulated synthesis of TNF- $\alpha$ and induced spleen growth, although the effects produced by the majority of the $H$. pylori LPS samples analysed were less intensive than those produced by the $S$. typhimurium LPS. The immunological parameters analysed allowed the detection of two types of $H$. pylori LPS: one of low biological activity and one of high biological activity. The most active LPS was extracted from strains isolated from patients with increased mucous damage associated with epithelial regeneration. Surprisingly, these strains were $\operatorname{cag} A$ negative and belonged to a low virulence genotype according to $v a c A$ gene (s1bm2 and $s 2 \mathrm{~m} 2)$. The results suggest the need to re-evaluate the role of the LPS as a virulence factor for some strains of $H$. pylori.
\end{abstract}

\section{Introduction}

Helicobacter pylori is the main species involved in mucosal damage in the stomach [1]. The infection and persistence of $H$. pylori in the stomach have been associated with the appearance of more serious sequelae, such as MALT lymphoma and gastric carcinoma, pathologies that appear to develop within a specific subgroup of individuals [2,3]. An interesting challenge in this field is to identify host and bacterial factors that might be involved in the remarkable variability of the diseases seen in infected patients.

Bacterial factors that favour pathogenicity of the species include CagA and VacA proteins [3, 4], urease [5], flagella [6], adhesins [6] and lipopolysaccharide (LPS)

Received 20 Aug. 2001; revised version received 11 March 2002; accepted 9 April 2002.

Corresponding author: Dr A. García (e-mail: apgarcia@ udec.cl/f@salgado.as).
$[7,8]$. Of these, LPS has received less attention as a virulence factor in $H$. pylori, although variability in sugar and fatty acid composition as well as antigenicity have been observed [9-11]. Moreover, the role of LPS in ulcero-peptic disease has been questioned [12]. However, the increased evidence of the participation of LPS as an important virulence factor for gram-negative bacteria during infection, and the knowledge accumulated on their biological effects both in vitro and in vivo, suggest that this macromolecule might play a role in the inflammatory response and gastric epithelial damage observed in vivo during $H$. pylori infection $[13,14]$.

Keeping in mind the world-wide prevalence of $H$. pylori infection and the great impact of gastroduodenal diseases in health care, this laboratory has initiated an epidemiological surveillance of the $H$. pylori infection in Concepcion, Chile, and a systematic study of the virulence factors of the species by investigating clinical isolates obtained from different diseases associated 
with H. pylori. Specifically, the effort has been concentrated on evaluating some immunological properties of $H$. pylori LPS, such as induction of mitogenicity, secretion of TNF- $\alpha$ and spleen growth, by the use of a mouse model.

This paper presents evidence of discrepancies between traditional genetic markers of virulence and immunological properties of $H$. pylori LPS that might contribute to the virulence and pathogenicity of particular strains.

\section{Materials and methods}

\section{Mice}

Female Rockefeller mice aged 7-8 weeks were used in the assays. Before the experiments, the animals were fed with extruded pellets and maintained under controlled environmental conditions $\left(25^{\circ} \mathrm{C}\right.$ and free access to water and food) for 1 week. The mice were handled according to the animal research guidelines of the Universidad de Concepción.

\section{Bacterial strains and growth conditions}

Eight strains of $H$. pylori were used in this study. The reference strain ATCC 43504 was a gift from Dr Arturo Yudelevich, Bios Chile Laboratory, Santiago, Chile. The other seven strains were isolated from gastric biopsies from patients with different gastric diseases (Table 1). The biopsies were macerated in 3-5 drops of saline solution, and the emulsions were inoculated on agar plates. All the cultures were performed on Columbia Agar (Merck Chemical Co., USA) supplemented with human defibrinated blood 5\% and Dent inhibitors mix (Oxoid). The plates were incubated under micro-aerobic conditions [15] at $37^{\circ} \mathrm{C}$ for $96 \mathrm{~h}$ [16].

\section{Identification of strains}

Strains were identified by colony morphology, Gram's stain and determination of urease, oxidase and catalase activities [17].

\section{Histopathological diagnosis}

Biopsy specimens were fixed in buffered formalin $10 \%$, embedded in paraffin, sectioned and stained as described previously for routine analysis [18]. Chronic gastritis, neutrophil infiltration and density of $H$. pylori was graded as suggested by the Updated Sydney System [18].

\section{PCR-based vacA and cagA genotyping}

Stock cultures of $H$. pylori were stored at $-70^{\circ} \mathrm{C}$ under micro-aerophilic conditions as described above, and total DNA was obtained by suspending the cultures in $100 \mu \mathrm{l}$ of sterile distilled water, heated for $10 \mathrm{~min}$ in a boiling water bath and cooled on ice for an additional $10 \min [19]$.

The strains were typed by PCR with the vacA primers described by Atherton et al. [4,20] and the cagA primers described by Shimoyama et al. [21]. PCR amplification was performed in an automated thermal cycler (Perkin-Elmer 480 thermocycler) in $50 \mu \mathrm{l}$ of reaction mixture containing the following reagents: $50-100 \mathrm{ng}$ of total DNA as template, $1.5 \mathrm{mM} \mathrm{MgCl}_{2}$, $100 \mu \mathrm{M}$ NTPs, $500 \mu \mathrm{M}$ primers and Taq polymerase $1 \mathrm{U}$. The reaction mixtures were heated initially to $95^{\circ} \mathrm{C}$ for $120 \mathrm{~s}$ and then underwent 40 cycles of $60 \mathrm{~s}$ at $95^{\circ} \mathrm{C}, 60 \mathrm{~s}$ at $50^{\circ} \mathrm{C}$ and $60 \mathrm{~s}$ at $72^{\circ} \mathrm{C}$. After cycling, the products were extended for a further $5 \mathrm{~min}$ at $72^{\circ} \mathrm{C}$.

\section{LPS extraction}

LPS was extracted from bacterial cultures by the hot phenol-water technique described by Westphal and Jann [22]. The crude LPS preparations were further purified by treatment with lysozyme $25 \mathrm{mg} / \mathrm{L}$, DNAase

Table 1. H. pylori strains isolated from patients with upper gastrointestinal symptoms used in this study: source, endoscopic and histopathological diagnosis, $\operatorname{cag} A$ status and $v a c A$ genotype of the strains

\begin{tabular}{|c|c|c|c|c|c|c|c|}
\hline \multirow{3}{*}{$\begin{array}{l}\text { Strain } \\
\text { no. }\end{array}$} & \multicolumn{2}{|c|}{ Patient } & \multirow{3}{*}{$\begin{array}{c}\text { Endoscopic } \\
\text { diagnosis }\end{array}$} & \multirow{3}{*}{$\begin{array}{c}\text { Histopathological } \\
\text { diagnosis }\end{array}$} & \multirow[b]{3}{*}{$\operatorname{cag} A$} & \multirow{2}{*}{\multicolumn{2}{|c|}{ Allelic $v a c A$ gene }} \\
\hline & \multirow{2}{*}{$\begin{array}{c}\text { age } \\
\text { (years) }\end{array}$} & \multirow[b]{2}{*}{ sex } & & & & & \\
\hline & & & & & & $\mathrm{s}$ & $\mathrm{m}$ \\
\hline 839 & 38 & $\mathrm{~F}$ & NUD & $\mathrm{ACG} / \mathrm{ER}$ & - & s1b & $\mathrm{m} 2$ \\
\hline 128 & 48 & $\mathrm{~F}$ & PUD & $\mathrm{ACG} / \mathrm{ER}$ & - & s2 & $\mathrm{m} 2$ \\
\hline 174 & 57 & M & PUD & AMCG & - & s1b & $\mathrm{m} 1$ \\
\hline 133 & 70 & $\mathrm{~F}$ & GC & ALCG & + & s2 & $\mathrm{m} 2$ \\
\hline 175 & 43 & M & NUD & $\mathrm{AMCG}$ & - & s1b & $\mathrm{m} 2$ \\
\hline 204 & 38 & $\mathrm{~F}$ & NUD & AMCG & + & s2 & $\mathrm{m} 2$ \\
\hline 630 & 54 & $\mathrm{~F}$ & NUD & ALCG & + & $\mathrm{s} 1 \mathrm{~b}$ & $\mathrm{~m} 2$ \\
\hline 43504 & UN & UN & UN & $\mathrm{AMCG}$ & + & s1a & $\mathrm{m} 1$ \\
\hline
\end{tabular}

M, male; F, female; s, vacA signal sequence; $\mathrm{m}, v a c A$ middle region; PUD, peptic ulcer disease; GC, gastric cancer; NUD, non-ulcerous dyspepsia; UN, unknown; ACG/ER, active chronic gastritis associated with epithelial regeneration; AMCG, active moderate chronic gastritis; ALCG, active light chronic gastritis. 
I $25 \mathrm{mg} / \mathrm{L}$ and RNAase $25 \mathrm{mg} / \mathrm{L}$ (all from Sigma) for $3 \mathrm{~h}$ at $37^{\circ} \mathrm{C}$. Then, proteinase $\mathrm{K}$ (Sigma) $50 \mathrm{mg} / \mathrm{L}$ was added and the preparations were incubated for further $2 \mathrm{~h}$ at $60^{\circ} \mathrm{C}$. Proteinase $\mathrm{K}$ was removed from the extracts by washing of LPS in pyrogen-free water followed by centrifugation at $105000 \mathrm{~g}$ (Sorvall RC-2B, rotor SS34). Each pellet containing pure LPS fraction was lyophilised and kept at $-20^{\circ} \mathrm{C}$ until use.

\section{Limulus amoebocyte lysate (LAL) assay}

The endotoxic activity was evaluated semi-quantitatively with a Limulus test (sensitivity $0.06 \mathrm{UE} / \mathrm{ml}$ ) (Pyrotell) according to the manufacturer's directions.

\section{B-cell proliferation}

Assays were performed as described previously [23], in triplicate. Briefly, spleen cells were suspended in RPMI 1640 medium containing fetal calf serum $10 \%$, penicillin $100 \mathrm{U} / \mathrm{ml}$, streptomycin $100 \mathrm{mg} / \mathrm{L}$ and amphotericin B $0.25 \mathrm{mg} / \mathrm{L}$ (all from Sigma) and adjusted to $4 \times 10^{6}$ cells $/ \mathrm{ml}$. Equal $100-\mu 1$ portions of cell suspension and LPS preparation (containing 0.1, 1.0 and $10 \mu \mathrm{g}$, respectively) were deposited in 96-well plates (Nunclon, Denmark) and incubated for $72 \mathrm{~h}$ at $37^{\circ} \mathrm{C}$, in air with $\mathrm{CO}_{2} 5 \%$. Then, cultures were pulse-labelled with $0.5 \mu \mathrm{Ci}$ of ${ }^{3} \mathrm{H}$-thymidine $(50 \mathrm{Ci} / \mathrm{mmol}$; Amersham, London) and incubation was continued for a further $18 \mathrm{~h}$. The cells were harvested by filtration and the radioactivity was measured in a liquid scintillation counter (Analyzer Tri-Carb 1600TR, Packard Instruments, USA). Commercial LPS (Sigma) from a wildtype strain of Salmonella typhimurium and its isogenic Re mutant (strain SL 1181; Sigma) were used as positive controls; RPMI 1640 medium was the negative control. All assays were conducted in triplicate.

\section{TNF- $\alpha$ determination}

Spleen cell suspensions were obtained and challenged with $10 \mu \mathrm{g}$ of LPS as described above, but for a period of $24 \mathrm{~h}$. The stimulated cells were concentrated by low speed centrifugation as described previously [24] and TNF- $\alpha$ was determined in the supernates of cell cultures by a Mouse TNF- $\alpha$ ELISA kit (BioSource International, Camarillo, USA), according to the manufacturer's instructions. Positive and negative controls were the same as those used for B-cell proliferation assays.

\section{Splenic index}

Blastogenic response was evaluated by the ability of LPS to induce spleen growth, expressed as a splenic index $=[$ spleen weight $(\mathrm{g}) /$ mouse weight $(\mathrm{g})] \times 1000$ [24]. Briefly, groups of four female mice were inoculated intraperitoneally with $10 \mu \mathrm{g}$ of LPS and killed after 4 days by cervical dislocation to allow extraction of the spleen. The weights of both the spleen and the mouse were measured to calculate the splenic index. Positive controls were the same as those used for B-cell proliferation assays and isotonic saline solution was used as negative control. The results are presented as the arithmetic means for each group of mice.

\section{Statistical analysis}

All the results were submitted to statistical analysis by the Tukey test, with the Systat computing programme [25].

\section{Results}

In this study, pure LPS preparations obtained from clinical strains of $H$. pylori were used to challenge mouse spleen cells or mice to evaluate the ability of these preparations to elicit an immunological response both in vitro and in vivo, respectively.

The strains used in this study were isolated from patients with diverse underlying illnesses (Table 1), including one isolated from a patient with gastric carcinoma (strain 133). All the strains belonged to a low virulence genotype according to the type of middle region vacA allele (m2), except strain 174, which had an $\mathrm{ml}$ genotype.

Pure LPS obtained from each strain, including the $H$. pylori ATCC 43504 control strain, was shown to be positive by the Limulus amoebocyte lysate test $(\geqslant 0.06$ endotoxin units $/ \mathrm{ml}$ ).

The immunological assays with pure LPS preparations were also shown to be mitogenic for mouse spleen cells (Table 2), although to a lesser extent than the commercial S. typhimurium smooth and rough LPS. Also, differences in the intensity of the biological activity among the $H$. pylori LPS were observed. Strains 128 and 839 showed high mitogenic activity (when cells were stimulated with $10 \mu \mathrm{g}$ of LPS) and highly increased ability to induce TNF- $\alpha$ secretion, comparable with the positive controls of $S$. typhimurium LPS (Fig. 1). The differences in mitogenicity observed between these LPS extracts and negative control were statistically significant $(p \leqslant 0.05)$ and showed no significant differences from the positive control, as determined by the Tukey test. On the other hand, the LPS from H. pylori ATCC 43504 was the least active of all the LPS assayed, with biological activity only higher than the negative control.

The in-vivo assay confirmed the findings observed in vitro, as $100 \%$ of the $H$. pylori LPS induced spleen growth in mice (Fig. 2). Again, two groups of $H$. pylori LPS were observed, one of low activity (strains 133, 174, 175, 204, 630 and ATCC 43504) and one of high activity (strains 128 and 839), with splenic index values of 9.5 and 10.3, respectively. S. typhimurium LPS 
Table 2. Mitogenicity induced by $H$. pylori LPS extracts

\begin{tabular}{lcrr}
\hline & \multicolumn{3}{c}{ Mean $(\mathrm{SD}){ }^{3} \mathrm{H}$-thymidine uptake $(\mathrm{cpm})$} \\
\cline { 2 - 4 } Strain no. & 0.1 & 1 & 10 \\
\hline H. pylori 128 & $1072(12.0)$ & $3503(6.5)$ & $30098(141.4)$ \\
H. pylori 133 & $1810(26.1)$ & $2466(34.2)$ & $6856(19.2)$ \\
H. pylori 174 & $1283(29.2)$ & $4366(35.1)$ & $13854(70.3)$ \\
H. pylori 175 & $1946(7.4)$ & $9802(15.9)$ & $10444(84.8)$ \\
H. pylori 204 & $946(3.8)$ & $2894(10.2)$ & $10833(101.8)$ \\
H. pylori 630 & $1507(25.0)$ & $3347(38.8)$ & $7714(29.9)$ \\
H. pylori 839 & $1154(4.5)$ & $3400(38.3)$ & $27030(379.6)$ \\
H. pylori ATCC43504 & $2080(18.7)$ & $3913(37.6)$ & $6382(60.8)$ \\
S. typhimurium (smooth) & $5492(23.9)$ & $10226(72.1)$ & $45120(141.0)$ \\
S. typhimurium (rough) & $6938(14.6)$ & $12242(49.5)$ & $56645(283.0)$ \\
\hline
\end{tabular}

Mouse spleen cells $\left(4 \times 10^{6}\right.$ cells $\left./ \mathrm{ml}\right)$ were challenged for $72 \mathrm{~h}$ with various amounts of $H$. pylori LPS, pulse-labelled and counted to determine mitogenicity as described in Materials and methods. Each value represents the mean of three independent readings.

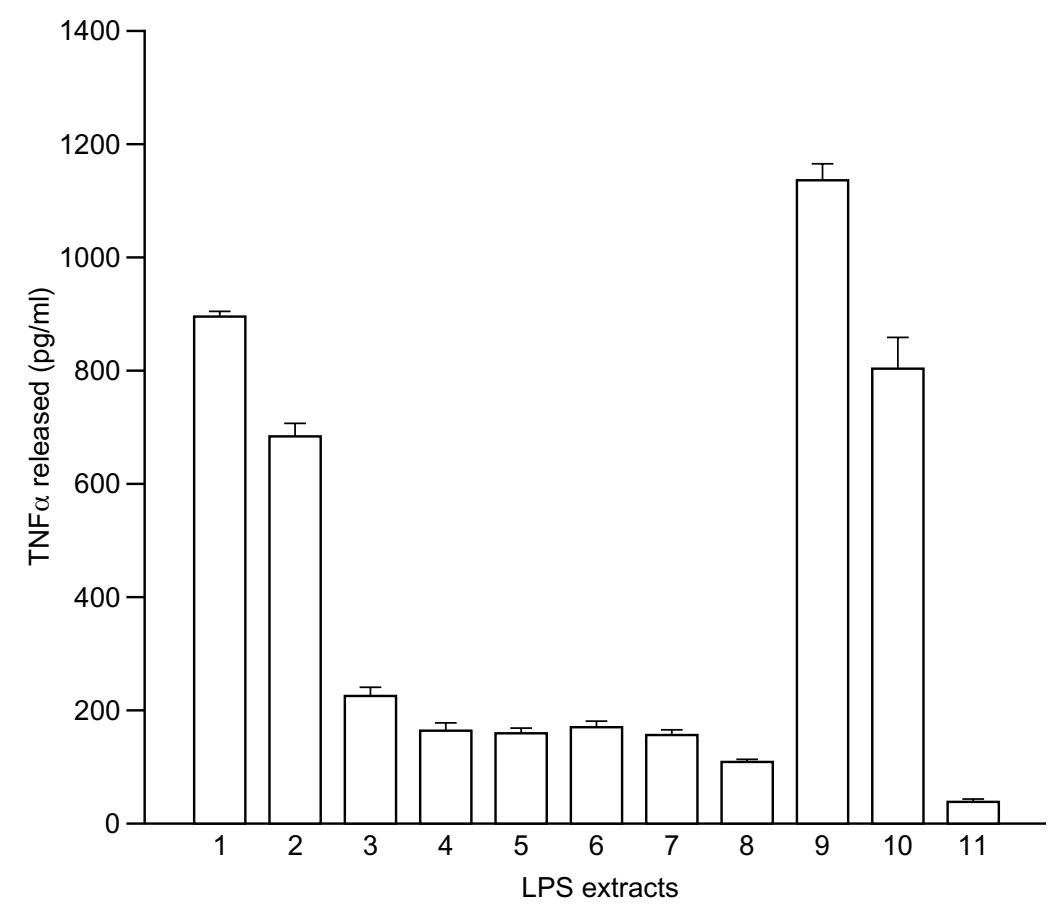

Fig. 1. Cytokine synthesis induced by H. pylori LPS extracts. A fraction of the induced cell mixture was centrifuged at $24 \mathrm{~h}$ after challenge with $10 \mu \mathrm{g}$ of LPS, and TNF- $\alpha$ was evaluated in the supernate with a mouse TNF- $\alpha$ ELISA kit. Each value represents the mean of three independent readings. 1, strain 128; 2, strain 839; 3, strain 174; 4, strain 175; 5, strain 630; 6, strain 204; 7, strain 133; 8, strain ATCC 43504; 9, rough LPS from S. typhimurium; 10, smooth LPS from S. typhimurium; 11, negative control (RPMI medium).

showed splenic index values of 13.5 for rough LPS and 10.8 for the smooth LPS.

\section{Discussion}

During the last two decades, H. pylori has caused great interest because of its high incidence as the aetiological agent of gastroduodenal diseases, including gastric adenocarcinoma [2]. However, the mechanisms involved in the pathogenesis of the species are still controversial, and the virulence factors are not well established. The results presented in this paper support the idea that LPS might play a crucial role as a pathogenic factor in H. pylori infection, particularly as it is known that several bacterial products - i.e., urease, cytotoxin or LPS - are released to the epithelium during infection, thus inducing an inflammatory response in the host $[26,27]$. Nonetheless, the importance of LPS as an inducer and maintenance factor in gastric disorders has been widely accepted only during the last few years, after the description of clinical strains with unusual LPS [9, 28].

Genetic approaches to detect more aggressive strains in clinical isolates of $H$. pylori have failed to explain the origin of several diseases, because genetically typed virulent strains have been isolated from asymptomatic individuals and low virulence genotypes have also been isolated from symptomatic patients [29]. These results indicate that new approaches are needed to understand the organic responses against $H$. pylori infection in man, and that strains with low virulence vacA alleles should not be disregarded and should be analysed for 


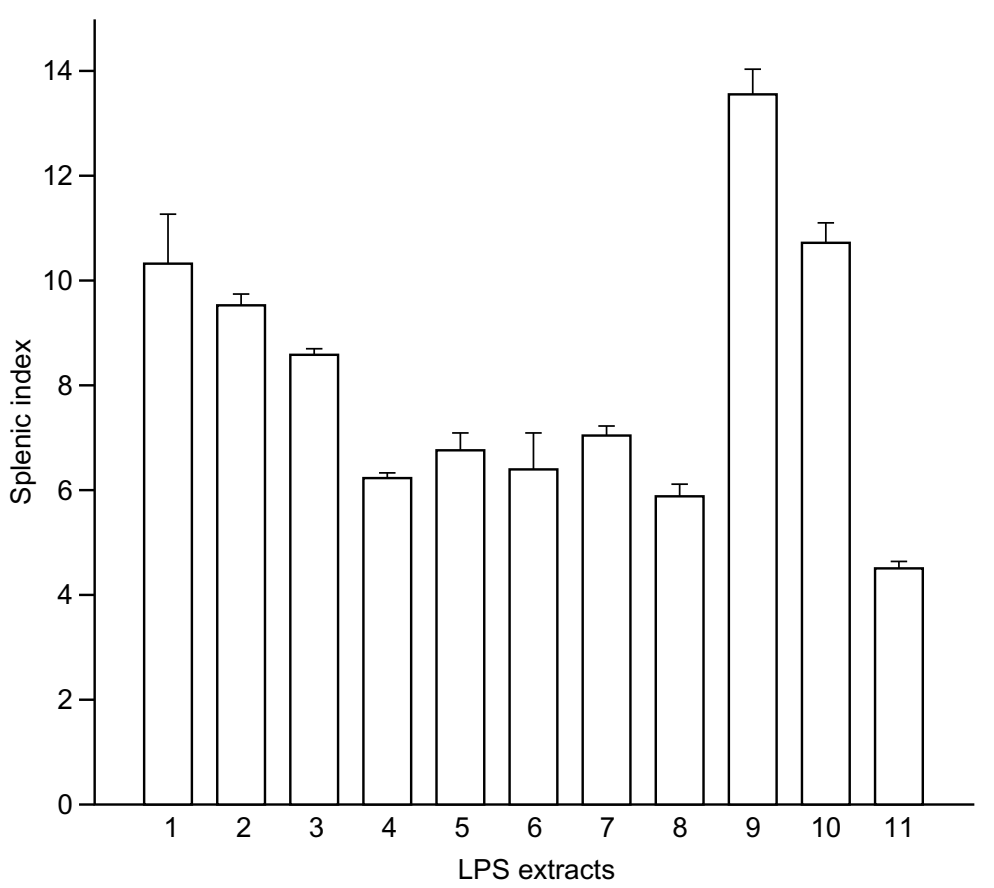

Fig. 2. Spleen growth induced by H. pylori LPS. Four female mice were inoculated intraperitoneally with $10 \mu \mathrm{g}$ of LPS and killed after 4 days by cervical dislocation to extract the spleen, and the splenic indices were calculated (see Materials and methods). LPS extracts were the same as Fig. 1.

other attributes of virulence, such as biological activity of LPS, as it is known that this macromolecule is involved in events that induce epithelial disorganisation and mimicry in gastric epithelium $[13,14]$.

Interestingly, the two LPS extracts that have biological activity comparable to $S$. typhimurium LPS in all the assays were isolated from patients who had intestinal metaplasia. On the other hand, both strains were $\operatorname{cag} A$ negative and had low virulence vacA genotypes (middle region $\mathrm{m} 2$ ), which have been associated with production of vacuolating cytotoxin of poor vacuolating activity and low levels of interleukin (IL)-8 secretion in in-vitro assays [30]. The increased response against these LPS preparations that were observed in mice might be a consequence of the experimental quality of the lipid A and the better affinity of the endotoxin with the immunocompetent cells, resembling the behaviour of the gastric epithelium in vivo where free LPS interacts with epithelial cells [31], allowing the lipid A to reach the membrane and induce the release of proinflammatory cytokines such as TNF- $\alpha$, IL-1 and IL-6 $[13,32,33]$. It is known that these related activities regulate secretion of other cytokines in the gastric mucosa [5, 27].

The LPS extracts of the other six clinical strains and the control ATCC H. pylori strain were not recognised as strong antigens, as they showed a smaller although homogeneous mitogenic activity and TNF- $\alpha$ induction capacity, similar to the results published elsewhere for this pathogen [12]. Also, the differences in the ability of LPS from various isolates to elicit mitogenic activity and TNF- $\alpha$ synthesis could be caused by variations in the fatty acid content of lipid A, as has been demonstrated for the LPS of other pathogens [24].

In-vivo studies also showed the biological activity of LPS as an endotoxin (Fig. 2). This activity was positive for all isolates, although it is known that the murine model is more resistant to the endotoxic activity of LPS than man, so the in-vivo response against this macromolecule should be higher.

The results of the present study emphasise the need to re-evaluate the role of $H$. pylori LPS in the pathogenesis of the diseases caused by this species.

This work was supported by grant nos 98036014-6 and 99036017-1 from Dirección de Investigación, Universidad de Concepción and FONDECYT 1000431, Concepción, Chile. We thank Dr Alejandra Martínez for help with PCR typing of the strains, Dr Homero Urrutia for statistical analysis of the results and María E. Larenas for her assistance with English language revision of the manuscript.

\section{References}

1. Blaser MJ. Hypothesis on the pathogenesis and natural history of Helicobacter pylori-induced inflammation. Gastroenterology 1992; 102: 720-727.

2. Blaser MJ, Parsonnet J. Parasitism by the 'slow' bacterium Helicobacter pylori leads to altered gastric homeostasis and neoplasia. J Clin Invest 1994; 94: 4-8.

3. Day AS, Jones NL, Lynett JT et al. cagE is a virulence factor associated with Helicobacter pylori-induced duodenal ulceration in children. $J$ Infect Dis 2000; 181: 1370-1375.

4. Atherton JC, Cao P, Peek RM, Tummuru MKR, Blaser MJ, Cover TL. Mosaicism in vacuolating cytotoxin alleles of Helicobacter pylori. Association of specific vacA type with cytotoxin production and peptic ulceration. J Biol Chem 1995; 270: $17771-17777$.

5. Hazell S, Lee A, Brady L, Hennessy W. Campylobacter 
pyloridis and gastritis: association with intracellular spaces and adaptation to an environment of mucus as important factors in colonization of the gastric epithelium. J Infect Dis 1986; 153: $658-663$.

6. Axon AT. Helicobacter pylori infection. J Antimicrob Chemother 1993; 32 Suppl A: 61-68.

7. Kimmel B, Bosserhoff A, Frank R, Gross R, Goebel W, Beier D. Identification of immunodominant antigens from Helicobacter pylori evaluation of their reactivities with sera from patients with different gastroduodenal pathologies. Infect Immun 2000; 68: 915-920.

8. Yokota S-I, Amano K-I, Hayashi S, Kubota T, Fujii N, Yokochi T. Human antibody response to Helicobacter pylori lipopolysaccharide: presence of an immunodominant epitope in the polysaccharide chain of lipopolysaccharide. Infect Immun 1998; 66: 3006-3011.

9. Monteiro MA, Appelmelk BJ, Rasko DA et al. Lipopolysaccharide structures of Helicobacter pylori genomic strains 26695 and J99, mouse model $H$. pylori Sydney strain, $H$. pylori $\mathrm{P} 466$ carrying sialyl Lewis $\mathrm{X}$, and $H$. pylori UA915 expressing Lewis B: classification of $H$. pylori lipopolysaccharides into glycotypes families. Eur J Biochem 2000; 267: 305-320.

10. Perez-Perez GI, Blaser MJ. Conservation and diversity of Campylobacter pyloridis major antigens. Infect Immun 1987; 55: $1256-1263$.

11. Yokota S-I, Amano K-I, Shibata Y et al. Two distinct antigenic types of the polysaccharide chains of Helicobacter pylori lipopolysaccharides characterized by reactivity with sera from humans with natural infection. Infect Immun 2000; 68: 151-159.

12. Muotiala A, Helander IM, Pyhala L, Kosunen TU, Moran LAP. Low biological activity of Helicobacter pylori lipopolysaccharide. Infect Immun 1987; 60: 1714-1716.

13. Slomiany BL, Piotrowski J, Sengupta S, Slomiany A. Inhibition of gastric mucosal laminin receptor by Helicobacter pylori lipopolysaccharide. Biochem Biophys Res Commun 1991; 175 : 963-970.

14. Trust TJ, Doig P, Emody L, Kienle Z, Wadstrom T, O'Toole P. High-affinity binding of the basement membrane proteins collagen type IV and laminin to the gastric pathogen Helicobacter pylori. Infect Immun 1991; 59: 4398-4404.

15. Gilbert JV, Ramakrishna J, Sunderman FW, Wright A, Plaut AG. Protein Hpn: cloning and characterization of a histidinerich metal-binding polypeptide in Helicobacter pylori and Helicobacter mustelae. Infect Immun 1995; 63: 2682-2688.

16. Xia H-X, Keane CT, Chen $\mathrm{J}$ et al. Transportation of Helicobacter pylori cultures by optimal systems. J Clin Microbiol 1994; 32: 3075-3077.

17. Schnell GA, Schubert TT. Usefulness of culture, histology, and urease testing in detection of Campylobacter pylori. Am J Gastroenterol 1989; 84: 133-137.

18. Dixon MF, Genta RM, Yardley JH, Correa P. Classification and grading of gastritis. The Updated Sydney Sistem. Am J Surg Pathol 1996; 20: 1161-1181.

19. Mazurier S, van de Giessen A, Heuvelman K, Wernars K. RAPD analysis of Campylobacter isolates: DNA fingerprinting without the need to purify DNA. Lett Appl Microbiol 1992; 14: 260-262.

20. Atherton JC. Molecular methods for detecting ulcerogenic strains of $H$. pylori. In: Clayton CL, Mobley HLT (eds) Helicobacter pylori protocols. New Jersey, Humana Press. 1997: 133-143.

21. Shimoyama T, Fukuda S, Tanaka M, Mikami T, Saito Y, Munakata A. High prevalence of the cagA-positive Helicobacter pylori strains in Japanese asymptomatic patients and gastric cancer patients. Scand J Gastroenterol 1997; 32: 465-468.

22. Westphal O, Jann K. Bacterial lipopolysaccharides, Extraction with phenol-water and further applications of the procedure. In: Whistler R (ed) Methods in carbohydrate chemistry, vol 5. New York, Academic Press. 1965: 83-91.

23. Folch H, Oñate A. Propiedades mitogénicas y caracterización de diferentes fracciones polisacáridas obtenidas de dos especies de Brucella. Arch Med Vet 1995; 27: 85-91.

24. García A, Salgado F, Solar H, González C, Zemelman R, Oñate A. Some immunological properties of lipopolysaccharide from Acinetobacter baumannii. J Med Microbiol 1999; 48: $479-483$.

25. Wilkinson L. Systat. The system for statistics. Evanston, IL, Systat. 1990.

26. Prins JM, van Deventer SJ, Kuijper EJ, Speelman P. Clinical relevance of antibiotic-induced endotoxin release. Antimicrob Agents Chemother 1994; 38: 1211-1218.

27. Smoot DT. How does Helicobacter pylori cause mucosal damage? Direct mechanisms. Gastroenterology 1997; 113 (6 Suppl): S31-S34.

28. Gibson JR, Chart $\mathrm{H}$, Owen RJ. Intra-strain variation in expression of lipopolysaccharide by Helicobacter pylori. Lett Appl Microbiol 1998; 26: 399-403.

29. Lee A, Fox J, Hazell S. Pathogenicity of Helicobacter pylori: a perspective. Infect Immun 1993; 61: 1601-1610.

30. Bliss CM, Linevsky JK, Golenbock DT, Keates S, Kelly CP. Helicobacter pylori lipopolysaccharide binds to CD14 and stimulates release of interleukin-8, epithelial neutrophilactivating peptide 78 , and monocyte chemotactic protein 1 by human monocytes. Infect Immun 1998; 66: 5357-5363.

31. Moran AP, Lindler B, Walsh EJ. Structural characterization of the lipid A component of Helicobacter pylori roughand smooth-form lipopolysaccharides. J Bacteriol 1997; 179: 6453-6463.

32. Henderson B, Poole S, Wilson M. Bacterial modulins: a novel class of virulence factors which cause host tissue pathology by inducing cytokine synthesis. Microbiol Rev 1996; 60: 316-341.

33. Kirkland T, Viriyakosol S, Perez-Perez GI, Blaser MJ. Helicobacter pylori lipopolysaccharide can activate $70 \mathrm{Z} / 3$ cells via CD14. Infect Immun 1997; 65: 604-608. 